de la variation lumineuse de l'étoile, les relevés de ces points, faits à l'aide de la courbe déformée, seront probablement affectés d'erreurs systématiques.

Pour le vérifier, j'ai rapproché dans la figure ci-jointe les quatre courbes de lumière, en prenant pour origine commune le maximum, et en leur donnant à toutes la même amplitude (celle de la courbe de M. Sawyer) à l'aide des formules suivantes:

$$
\begin{aligned}
& \text { Sawyer }=-5^{\mathrm{d}} \cdot 2+1.47 \text { Chandler } \\
& \text { Sawyer }=+2.0+1.59 \text { Yendell } \\
& \text { Sawyer }=+0.4+1.25 \text { Luizet }
\end{aligned}
$$

Ces quatre courbes concordent assez bien dans la portion ascendante; mais dans la branche descendante la courbe de $M$. Chandler s'écarte notablement des 3 autres, et celle de $M$. Yendell reste, entre les degrés 17 et 10 de l'échelle de lumiêre, à peu près parallèle à celle de M. Sawyer, à une distance de o.̣. environ. En outre, d'après l'ensemble des observations, l'intervalle de temps qui sépare le maximum du minimum est de 3 j.o; cette valeur, qui serait respectivement de $3^{j} 3^{8}$ et $3^{\mathfrak{j}_{1}} \mathbf{5}_{5}$ d'après MM. Chandler et Yendell, est plus rapprochée de celles indiquées par la courbe de M. Sawyer et par la mienne.

Si donc on admet que la moyenne de ces deux dernières courbes représente exactement la variation lumineuse de $\mathbf{T}$ Petit Renard, on voit que le résidu moyen des déterminations des maxima faites par MM. Chandler et Yendell, à l'aide d'observations se rapportant à la période d'augmentation de l'éclat de l'étoile, sera à peu près nul, tandis qu'il sera positif pour $M$. Yendell, et négatif pour M. Chandler lorsque le maximum aura été déterminé à l'aide d'observations faites pendant la diminution de l'éclat.

La même discussion pourrait être faite par rapport au minimum; elle paraît justifier l'hypothèse précédente relative à l'influence du tracé de la courbe de lumière sur les relevés des points maxima et minima.

A priori, dans le calcul des éléments de la variation de l'étoile, ces erreurs systématiques ne doivent affecter que l'origine des maxima et des minima, sans changer la durée de la période. En effet, en calculant de nouveau ces éléments à l'aide des observations de MM. Sawyer et Luizet, on trouve (T.m. Paris):

Max. $2409849.02 \pm 0.03$ (1 $88_{5}$ novembre 3.02 )

Min. $2409847.61 \pm 0.06$ (1885 novembre $1.6 \mathrm{r}$ )

et

$$
4 \div 43578 \pm 0.00014
$$

pour la durée de la période.

La durée de la période est donc la même que celle trouvée à l'aide de toutes les observations, les origines seules sont un peu différentes.

Ces derniers éléments sont ceux que nous adopterons définitivement pour l'étoile $T$ Petit Renard.

St. Genis-Laval, 1900 avril 4.

M. Luizet.

\title{
El eclipse de Sol del 28 mayo 1900.
}

\section{De F. Comas Sold.}

Al objeto de estudiar este eclipse me trasladé á Elche (España). Mis aparatos consistran en una cámara prismática constituída por dos prismas de flint de $60^{\circ}$ colocados delante de un objetivo de $55 \mathrm{~mm}$ de diámetro y $80 \mathrm{~cm}$ de distancia focal y una cámara fotográfica de $1.60 \mathrm{~m}$ de longitud y objetivo astronómico de 1 I $\mathrm{cm}$. Los dos aparatos estaban montados sobre un mismo pie ecuatorial con aparato de relojería. Todas las placas empleadas son isocromáticas Ilford con antihalo. Desarrollo al pirogálico.

El tiempo favoreció admirablemente la observación de este eclipse, siendo sólo de lamentar la poca duración de la totalidad. No obstante de ello, pude sacar dos clichés espectroscópicos de la cromósfera y dos fotografías de la corona, además de un espectro de comparación obtenido $30^{\mathrm{s}}$ antes del principio de la totalidad. En este espectro se percibe una multitud de rayas negras, sobre todo hacia la región quimica, apareciendo ya algunas de ellas invertidas. Tales son las rayas $H, K, F$ y otra, perteneciente quizás al titano y cuya longitud de onda es aproximadamente 4470 .

El primer cliché espectroscópico de la cromósfera lo obtuve en el momento de principiar la totalidad con una exposición de $2^{5}$. Aparece bastante rico de rayas, pudiéndose contar más de 120 . Las más intensas son las $H$ y $K$ y las del hidrógeno, asi en la región visible como en la ultraviolada. Es muy fuerte también la $D_{3}$ y se distinguen admirablemente la doble $b$ del magnesio, algunas del titano, muchas del hierro, etc. La $1474 K$ de la corona es muy débil, pero perfectamente perceptible. En otro trabajo daré la lista completa de las rayas visibles con su longitud de onda, cosa que me es ahora imposible por carecer de mo. mento de un buen aparato de medida.

La segunda fotografía espectroscópica la obtuve pasados $25^{\mathrm{s}}$ desde el principio de la totalidad, dando á la placa $4^{5}$ de exposicion. En esta fotografía han desaparecido casi todas las rayas. Sólo quedan la $H$ y $K$, muy fuertes y dibujando todo el contorno de la cromósfera con sus protuberancias, y otras del hidrógeno, pero en éstas casi sólo son visibles las protuberancias, que aparecen en las imágenes monocromáticas de la cromósfera como pequeños puntos luminosos. Resulta pues que si la única sustancia productora de la $H$ y la $K$ es el calcio, este gas metálico incandescente es el más actínico ó el más elevado de la cromósfera. Su espesor medio no baja de 22". En el trabajo ulterior á que he hecho referencia precisaré numéricamente los resultados de mis clichés.

Las dos fotografias de la corona muestran multitud de detalles. Una de ellas, la del medio de la totalidad, es dulce; la otra, la del final de la totalidad, es dura. La dulce permite distinguir buen número de pequeñas protuberancias, que nadie señaló á simple vista. La dura acusa de una manera notable la estructura de la corona. Esta aparece formada de filamentos luminosos, semejando en con- 
junto á una caballera de luz. El tipo de la corona es exactamente el mismo que le corresponde en la época de minima actividad solar: es decir, grandes expansiones ecuatoriales, formadas de filamentos y haces luminosos arqueados ó convergentes hacia el ecuador solar, y plumeros ó abanicos de luz en los casquetes polares. La expansión coronal del W alcanza en los clichés hasta casi 3 veces el radio solar. Los plumeros polares son muy regulares y parecidos á los rayos de Sol que pasan por entre las nubes. El eje de simetria de estos plumeros corresponde sensiblemente á la dirección del eje solar, conforme me ha confirmado el cálculo de orientación apoyado en Mercurio, que aparece en los mismos clichés de la corona.

Muy poco pude mirar directamente el eclipse, atareado

Barcelona, Observatorio privado, 1900 Junio 15. como estaba manejando los aparatos; á pesar de todo, en los pocos segundos que pude dedicarme á ello, me convenci de que la coloración era sensiblemente nula en la corona. Ofrecta un tono blanco, argentino, siendo visibles muchisimos menos detalles que en las fotografias.

El termómetro de bola negra señaló un descenso máximo de temperatura de $12 \% 5$. El barómetro nada interesante indicó. En el momento de la totalidad, la luz era bastante intensa para poder leer perfectamente un tipo de imprenta ordinario. Se notaba muy bien que la luz no procedía sólo de la corona, sino principalmente de la difusión luminosa de la atmósfera en las regiones próximas en que el eclipse no era total.

Osservazioni di pianetini

fatte coll' equatoriale di om25 di apertura del R. Osservatorio del Collegio Romano.

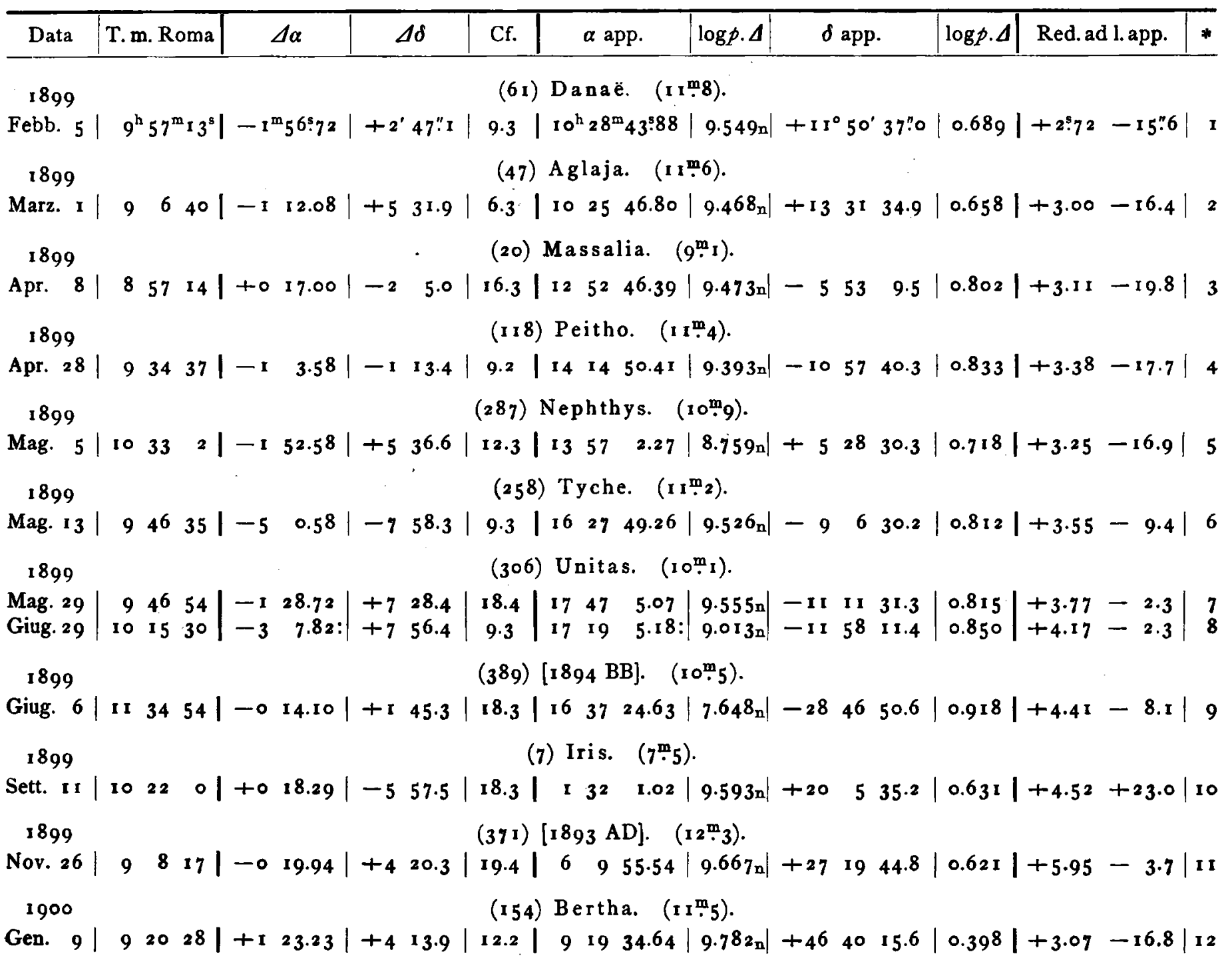

